\title{
OUTCOME OF LOCALLY ASSEMBLED CONTINOUS POSITIVE AIRWAY PRESSURE DEVICE IN NEONATES WITH RESPIRATORY DISTRESS IN LOW RESOURCE
}

\section{SETTINO}

Sabina Shrestha, ${ }^{1}$ Sujit Kumar Shrestha, ${ }^{1}$ Gentle Sunder Shrestha, ${ }^{2}$ Madhu Sudan Dhakal ${ }^{1}$

${ }^{1}$ Department of Pediatrics, Nepal Medical College and Teaching Hospital, Attarkhel, Gokarneshwor-8, ${ }^{2}$ Department of Anesthesia, Tribhuvan University Teaching Hospital, Maharajgunj, Kathmandu, Nepal,

\section{ABSTRACT}

Respiratory distress is the most frequent cause of neonatal admission in neonatal intensive care unit (NICU). Continuous Positive Airway Pressure (CPAP) is an effective mode of treatment in newborn with respiratory distress. CPAP is the application of positive pressure to the airways of spontaneously breathing patient throughout the respiratory cycle. Low cost CPAP can be locally assembled and used in neonates with respiratory distress to reduce the mortality. This is a cross sectional descriptive study conducted in NICU of Nepal Medical College Teaching Hospital from the period of June 2021 to September 2021 to assess the outcome of locally assembled CPAP. A total of 96 newborns with respiratory distress were included in the study. Severity of respiratory distress was assessed by Downes score. Downes score before and after CPAP were recorded. Newborn with Downes score of $\geq 4$ was started with locally assembled CPAP. Outcome was taken as improvement when the respiratory distress was decreased with Downes score $<4$. And it was taken as a failure when baby required mechanical ventilation. Mean Downes score before starting CPAP was 4.81 and after CPAP was 0.51 . Mean CPAP pressure was $4.27 \mathrm{~cm}$ of water. Outcome of study showed, 80 (83.3\%) babies were improved, 7 (7.3\%) had failed CPAP who required mechanical ventilation and 1 (1\%) baby expired. In conclusion, locally assembled CPAP shown to be equally effective as standard CPAP device and can be used as an effective alternative to mechanical ventilator in developing country with limited resource setting.

\section{KEYWORDS}

Locally assembled CPAP, respiratory distress, newborn

Received on: September 30, 2021

Accepted for publication: December 03, 2021

\section{CORRESPONDING AUTHOR}

Dr. Sabina Shrestha,

Associate Professor,

Department of Pediatrics,

Nepal Medical College and Teaching Hospital, Attarkhel, Gokarneshwor-8, Kathmandu, Nepal

Email: sabinajoshi1234@hotmail.com

Orcid No: https://orcid.org/0000-0003-4652-7492

DOI: https://doi.org/10.3126/nmcj.v23i4.42210 


\section{INTRODUCTION}

Respiratory disorders are the most frequent cause of admission in neonatal intensive care in both term and preterm infants. ${ }^{1}$ A previous study showed that $34.3 \%$ of neonatal admissions was due to respiratory distress in our hospital and it accounted for $12.8 \%$ of neonatal mortality. Meconium aspiration syndrome, septicemia and hyaline membrane disease are the most important causes of respiratory distress. ${ }^{2}$ Continuous Positive Airway Pressure (CPAP) is an effective mode of treatment in newborn with respiratory distress with significant clinical outcome. ${ }^{3}$ CPAP is the application of positive pressure to the airways of the spontaneously breathing patient throughout the respiratory cycle. It maintains inspiratory and expiratory pressures above ambient pressure, resulting in increased functional residual capacity, improvement in static lung compliance, and decreased airway resistance. ${ }^{4}$ CPAP is usually delivered through the mechanical ventilator. Bubble CPAP is a simplified, non-invasive method of delivering continuous positive airway pressure to the infant. ${ }^{5}$ Low cost CPAP can be locally assembled and used in neonates with respiratory distress to reduce the mortallity. ${ }^{6}$ Conventional CPAP and mechanical ventilator are expensive and required trained persons to operate. Though several conventional bubbled nasal CPAP devices are available; these facilities may not be easily available in the resource limited countries. This study was conducted to observe the outcome of low cost locally assembled CPAP in the neonates with respiratory distress.

\section{MATERIALS AND METHODS}

This was a cross sectional descriptive study conducted in NICU of Nepal Medical College Teaching Hospital from the period of June 2021 to September 2021. Ethical approval was obtained from Nepal Medical College Institutional Review Committee. All the term, preterm and post term babies who have respiratory distress with informed consent from the parents were included in the study. The syndromic babies and babies with lethal congenital anomalies were excluded from the study. Detail maternal and neonatal history was taken. Complete physical examination of all the newborn including head to toe examination was done. Gestational age was assessed using Modified Ballard Score. The newborn was considered to have respiratory distress when there was presence of at least two of the following criteria: respiratory rate of more than 60 per minute in quiet and resting baby, chest retraction and grunting. ${ }^{7}$

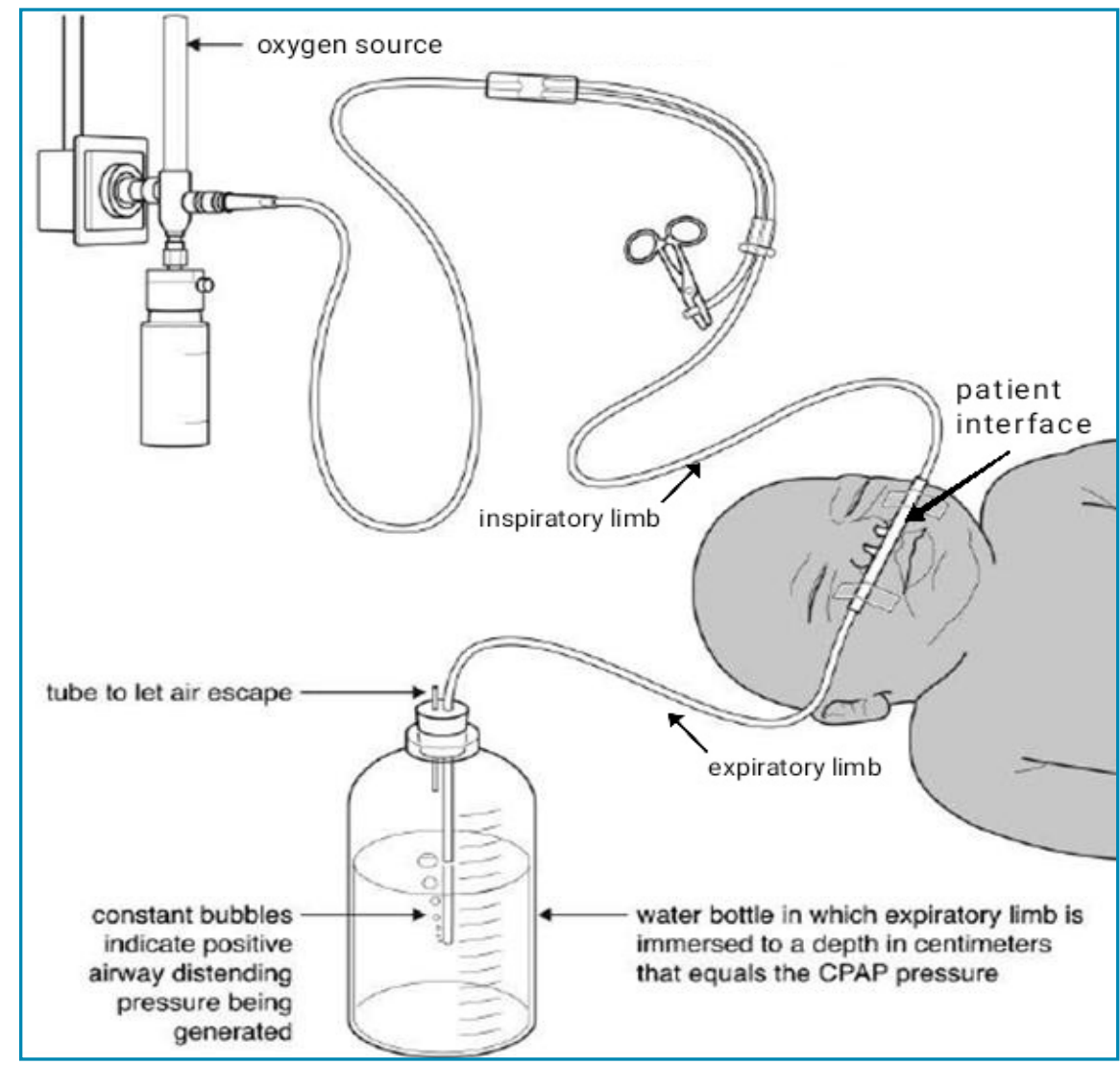

Fig. 1: Locally assembled CPAP delivery system 
All the newborn with respiratory distress eligible for inclusion were included in study. Severity of respiratory distress in neonate was assessed by Downes score. Based on Downes score new born has clinical respiratory distress when the score is $\geq 4$ and $>7$ indicate impending respiratory failure. ${ }^{8}$ Apgar score at 1 and 5 minutes was recorded. Newborn were assessed for signs of respiratory distress. Downes score before and after CPAP were recorded. Newborn with Downes score of $\geq 4$ was started with locally assembled CPAP.

Duration of CPAP with its outcome was noted. Outcome was taken as improvement when the respiratory distress was decreased with Downes score <4, patient was weaned from CPAP and the oxygen supply was delivered through the headbox. And it was taken as a failure when baby required mechanical ventilation. Neonates were also assessed for any complications of CPAP.

Our locally assembled CPAP delivery system included (Fig. 1):

a. Oxygen source: The oxygen flow rate usually varied from $5 \mathrm{~L} / \mathrm{min}$ to $10 \mathrm{~L} / \mathrm{min}$;

b. Inspiratory limb: It is the section of breathing circuit which consisted of nasal prong which was connected to oxygen source and patient interface;

c. Patient interface: Binasal prongs of appropriate size were used to set up the CPAP circuit. To prevent air leakage the patient interface was tightly sealed to patient nostril.

d. Expiratory limb: The nasal prong was cut on one side. The short limb of cut section was firmly tied to avoid air leak; the free end of the prong served as the expiratory limb. If the expiratory circuit was short, it could be attached to the intravenous fluid administering tube.

e. Pressure generating system: The expiratory limb of the nasal prong leading from the patient interface was immersed into a calibrated transparent container (or saline bottle) containing distilled water. The depth of immersion was equivalent to the CPAP pressure generated in $\mathrm{cm}$ of water (usually 4-6 cm). The tube was secured to the container by adhesive tape to ensure the depth of the immersed tube remained constant. The constant bubbling indicated that positive expiratory pressure was being generated. The tube or the opening in the container allowed the air to escape.
Data of the patient was collected in a preformed Proforma and analyzed using SPSS 16 software.

\section{RESULTS}

There were 96 newborns enrolled in the study who has signs of respiratory distress. Out of them $74(77.1 \%)$ were male and $22(22.9 \%)$ were female. There were $76(79.2 \%)$ term babies, $17(17.7 \%)$ pre-term and $3(3.1 \%)$ post

Table 1: Neonatal Characteristic $(n=96)$

\begin{tabular}{|c|c|c|}
\hline Variables & $\mathbf{n}$ & $\%$ \\
\hline \multicolumn{3}{|l|}{ Sex } \\
\hline Male & 74 & 77.1 \\
\hline Female & 22 & 22.9 \\
\hline \multicolumn{3}{|l|}{ Gestation } \\
\hline Preterm & 17 & 17.7 \\
\hline Term & 76 & 79.2 \\
\hline Post Term & 3 & 3.1 \\
\hline \multicolumn{3}{|l|}{ Birth Weight } \\
\hline$<1500 \mathrm{gm}$ & 6 & 6.2 \\
\hline $1500-<2500 \mathrm{gm}$ & 11 & 11.5 \\
\hline 2500-4000gm & 72 & 75.0 \\
\hline$>4000 \mathrm{gm}$ & 7 & 7.3 \\
\hline \multicolumn{3}{|l|}{ Mode of Delivery } \\
\hline Normal Vaginal & 27 & 28.2 \\
\hline Cesarean section & 68 & 70.8 \\
\hline Others & 1 & 1.0 \\
\hline \multicolumn{3}{|l|}{ Apgar Score(at 5 min) } \\
\hline$<5$ & 1 & 1.0 \\
\hline$<7$ & 5 & 5.2 \\
\hline$=>7$ & 90 & 93.8 \\
\hline \multicolumn{3}{|l|}{$\begin{array}{l}\text { Causes of Respiratory } \\
\text { Distress requiring CPAP }\end{array}$} \\
\hline Neonatal Sepsis & 26 & 27.1 \\
\hline Congenital Pneumonia & 18 & 18.7 \\
\hline $\begin{array}{l}\text { Transient Tachypnia of } \\
\text { newborn }\end{array}$ & 17 & 17.7 \\
\hline $\begin{array}{l}\text { Meconium aspiration } \\
\text { syndrome }\end{array}$ & 12 & 12.5 \\
\hline Hyaline Membrane Disease & 13 & 13.5 \\
\hline Birth Asphaxia & 10 & 10.5 \\
\hline
\end{tabular}


Table 2: Parameters under CPAP

\begin{tabular}{|c|c|c|}
\hline Parameters & Mean & Range \\
\hline \multicolumn{3}{|l|}{ Downes Score } \\
\hline Before CPAP & 4.81 & $4-8$ \\
\hline During CPAP & 4.23 & $4-7$ \\
\hline After CPAP & 0.5 & $0-2$ \\
\hline \multicolumn{3}{|l|}{ Respiratory Rate } \\
\hline Before CPAP & $76.59 / \mathrm{min}$ & $40-106$ \\
\hline After CPAP & $59.35 / \mathrm{min}$ & $40-90$ \\
\hline Mean CPAP pressure & $\begin{array}{c}4.27 \mathrm{~cm} \text { of } \\
\mathrm{H}_{2} \mathrm{O}\end{array}$ & $\begin{array}{c}3-6 \mathrm{~cm} \text { of } \\
\mathrm{H}_{2} \mathrm{O}\end{array}$ \\
\hline Duration of CPAP & 1.93 days & 1-8 days \\
\hline $\begin{array}{l}\text { Duration of hospital } \\
\text { stay }\end{array}$ & 8.5 days & 1-30 days \\
\hline
\end{tabular}

term babies (Table 1). Mean Downes score before starting CPAP was 4.81 and after CPAP was 0.51 . Mean CPAP pressure was $4.27 \mathrm{~cm}$ of water. Mean duration of CPAP was 1.93 days. Mean respiratory rate before starting CPAP was76.59 per minute which decreased to 59.35 per minute after CPAP (Table 2). It shows decreasing respiratory rate and Downes score after using locally assembled CPAP. Those neonates who required mechanical ventilation had severe respiratory distress with Downes score of 6-8 before starting CPAP. The neonates who required higher CPAP pressure had poor outcome. Out of 17 babies who required CPAP pressure 25,7 had failed CPAP requiring mechanical ventilation and among them one baby expired. On bivariate logistic regression, there was a non-significant association between mean CPAP pressure and a successful outcome $(p=0.09)$. Pneumothorax was seen in 3 babies and abdominal distension in 3 neonates which are the common complications of CPAP. Meconium stained liquor was one of the most important risk factor for respiratory distress in our study.

\section{DISCUSSION}

Respiratory distress is responsible for majority of neonatal admission to NICU. Various pulmonary and extra-pulmonary causes are responsible for respiratory distress. ${ }^{9}$ A study showed $34 \%$ cases were admitted in NICU with respiratory distress where the most common cause was transient tachypnea of newborn (44\%). ${ }^{10}$ Incidence is similar in our study where
Table 3: Outcome of neonate on CPAP $(n=96)$

\begin{tabular}{|lcc|} 
Outcome & $\mathbf{n}$ & $\mathbf{\%}$ \\
\hline Improved & 80 & 83.3 \\
CPAP failure requiring MV & 7 & 7.3 \\
DOR & 8 & 8.4 \\
Expired & 1 & 1.0 \\
\hline
\end{tabular}

28\% neonates were admitted with respiratory distress with most common cause being neonatal sepsis (27\%), followed by congenital pneumonia (18.75\%). Whereas in another study most common cause was meconium aspiration syndrome (21.1\%). ${ }^{2}$ The bubble continuous airway positive pressure for respiratory distress is effective and safe mode of treating mild to moderate respiratory distress. ${ }^{11}$ The neonates who are kept in bubble CPAP, improvement of respiratory distress was seen in $61 \%$ and only $39 \%$ needed mechanical ventilation. ${ }^{12}$ Our locally assembled CPAP has very good out come with improvement in 80 (83.3\%) cases, only 7 (7.3\%) cases required mechanical ventilator due to CPAP failure. Among the babies who were kept in mechanical ventilator only $1(1 \%)$ expired (Table 3$)$. Another study showed low cost locally assembled bubble CPAP device is comparable to the standard bubble CPAP used in the developed world. It delivers adequate pressure and flow to treat the children with compromised respiratory conditions and is inexpensive enough to use in the country with low resource setting. ${ }^{13}$ Low cost bubble CPAP has been proven to be safe and effective intervention in newborn with respiratory distress and it decreased the need of invasive ventilation which is associated with bronchopulmonary dysplasia. ${ }^{14}$

One of the important drawbacks of this locally assembled CPAP is; there is no oxygen/air blender to regulate the fraction of inspired oxygen concentration. Which increases the risk of retinopathy of prematurity (ROP) in preterm neonates. The risk can be decreased by doing regular screening for ROP in all the preterm newborn which we are doing in all the neonates below 35 weeks of gestation.

In conclusion, locally assembled CPAP has shown a very good outcome which can be comparable to more advanced devices such as Bubble CPAP and mechanical ventilator. The low cost of assemble makes it a viable option in low and middle income countries. So this low cost CPAP delivery system may be an 
effective alternative to mechanical ventilator in developing country with limited resource setting.
Conflict of interest: None

Source of research fund: None

\section{REFERENCES}

1. Shawn K, Ahlfeld. Respiratory tract disorder. In Kliegman RM, Blum NJ, Shah SS et al editors. Nelson Text Book of Pediatrics $\left(21^{\text {th }}\right.$ ed). Philadelphia: Elsevier 2020: 929-49.

2. Rijal P, Shrestha M. Senario of neonatal respiratory distress in tertiary hospital. J Nep Health Res Counc 2018; 16: 131-5.

3. Buckmaster A. Nasal continuous positive airway pressure for respiratory distress in non-tertiary care centres: what is needed and where to from here? J Paediatr Child Health 2012; 48: 747-52.

4. American Association of Respiratory Care. Application of continuous positive airway pressure to neonates via nasal prongs, nasopharyngeal tube or nasal mask-2004 revision \& update. Respir Care 2004; 49: 1100-8.

5. Eichenwald EC. Mechanical ventilation. In Cloherty JP, Eichenwald EC, Hansen AR, Stark AR, editors. Mannual of neonatal care ( $7^{\text {th }}$ ed). Philadelphia: Lippincott Williams \& Wilkins 2012: 331-42.

6. Daga S, Mhatre S, Borhade A, Khan D. Homemade continuous positive airway pressure device may reduce mortality in neonates with respiratory distress in neonate with respiratory distress in low resource setting. $J$ Trop Pediatr 2014; 60: 343-7.

7. Singh M. Care of the newborn. $5^{\text {th }}$ ed. New Delhi: Sagar Publications; 2002: 4.
8. Downes JJ, Vidyasagar D, Morrow GM, Boggs TR. Respiratory distress syndrome of newborn infant. Clin Pediatr 1970; 9: 325-31.

9. Sai SKM, Siva Sankara MYV, Yarakeswara RP, Madhusudhan K, Pundareekaksha V, Pathrudu GB. Approach to respiratory distress in the newborn. Int'l J Health Res Mod Integrated Med Sci 2015; 2: 24-35.

10. Barkiya SM, Venugopal N, Kumari V. Clinical -etiological profile and outcome of neonatal respiratory distress. Int'l J Sci Study 2016; 3: 18992.DOI:10.17354/ijss/2016/82.

11. Buch P, Makwana AM, Chudasama RK. Usefulness of Downe score as clinical assessment tool and bubble CPAP as primary respiratory support in neonatal respiratory distress syndrome. $J$ Pediatr Sci 2013; 5: e176.

12. Manandhar SR. Outcome of respiratory distress in neonate with bubble CPAP at neonatal intensive care unit of a tertiary hospital. J Nepal Med Assoc 2019; 57: 92-7.

13. Bennett DJ, Carroll RW, Kacmarek RM. Evaluation of a low-cost bubble CPAP system designed for resource limited settings. Respir Care 2018; 63: 395-403.

14. Egesa WI, Waibi WM. Bubble nasal continuous positive airway pressure (bNCPAP): An effestive low-cost intervention for resource -constrained settings. Int'l J Pediatr 2020; 9: https://doi. org/10.1155/2020/8871980. 